Article

\title{
Adapted Moderate Training Exercise Decreases the Expression of Ngal in the Rat Kidney: An Immunohistochemical Study
}

\author{
Michelino Di Rosa ${ }^{1,+} \oplus^{-}$, Paola Castrogiovanni ${ }^{1,+}\left(\mathbb{C}\right.$, Francesca Maria Trovato ${ }^{2}{ }^{(0)}$, \\ Lorenzo Malatino $^{2}$ (D), Silvia Ravalli ${ }^{1}$, Rosa Imbesi ${ }^{1}\left(D\right.$, Marta Anna Szychlinska ${ }^{1,} \neq(\mathbb{D}$ and \\ Giuseppe Musumeci ${ }^{1, *, \ddagger(D)}$ \\ 1 Department of Biomedical and Biotechnological Sciences, Human Anatomy and Histology Section, School of \\ Medicine, University of Catania, 95100 Catania, Italy; mdirosa@unict.it (M.D.R.); pacastro@unict.it (P.C.); \\ silviaravalli@gmail.com (S.R.); roimbesi@unict.it (R.I.); marta.sz@hotmail.it (M.A.S.) \\ 2 Department of Clinical and Experimental Medicine, School of Medicine, University of Catania, \\ 95100 Catania, Italy; trovatofrancesca@gmail.com (F.M.T.); Malatino@unict.it (L.M.) \\ * Correspondence: g.musumeci@unict.it; Tel.: +39-095-3782043 \\ + co-first authorship. \\ $\ddagger$ co-last authorship.
}

Received: 1 February 2019; Accepted: 8 March 2019; Published: 13 March 2019

\begin{abstract}
Neutrophil gelatinase-associated lipocalin (NGAL) is a biomarker of several injuries and is upregulated in inflammatory conditions. Vitamin D was shown to have anti-inflammatory effects and to increase after physical activity. This work aimed to assess, through immunohistochemistry, the effects of an adapted moderate training exercise (AMTE) on the expression of NGAL and vitamin $\mathrm{D}$ receptor (VDR) in the kidney and heart of rats. Sixteen rats were distributed into two groups: the sedentary control group and the experimental group, subjected to AMTE on the treadmill for 12 weeks. The results showed the basal expression of NGAL and VDR in both the heart and the kidney in sedentary rats; no differences in the expression of both NGAL and VDR in the heart; and a decreased NGAL and an increased VDR expression in the kidney of rats subjected to AMTE. These results suggest a possible protective role of AMTE on NGAL-associated injuries in the kidney, probably through the vitamin D signaling pathway. Our results represent an interesting preliminary data that may open new horizons in the management of NGAL-associated kidney injuries. However, further studies are needed to confirm these results and to comprehend the specific interaction between NGAL and VDR pathways in the kidney.
\end{abstract}

Keywords: training exercise; NGAL; VDR; kidney; heart; immunohistochemistry

\section{Introduction}

The adapted moderate training exercise (AMTE), corresponding to the adapted nonexhaustive aerobic physical activity is an exciting approach, is increasingly considered by the scientific community to prevent metabolic disabling diseases and increase physical well-being. Data from the literature show that moderate physical activity can reduce inflammation and improve general physical function in humans [1-9] and animals [10,11]. In a rat model, aerobic interval exercise protocol was shown to prevent the development of diabetic nephropathy and to affect the metabolism of certain minerals [12]. Moreover, aerobic training in association with L-arginine supplementation also demonstrated to ameliorate kidney and liver damage in myocardial infarction rats, via antioxidant mechanisms [13]. The expression of many cytokines and adipokines associated with metabolic syndrome has also been investigated in obese women, after aerobic training protocol, with positive results [14]. In recent 
literature, authors described that AMTE has beneficial effects on the preservation of articular cartilage and muscle tissues, confirming its protective role on the musculoskeletal system as well [15-18].

Neutrophil gelatinase-associated lipocalin (NGAL) is a small protein of the lipocalin superfamily, also known as lipocalin-2 [19]. It is physiologically and basally present at low levels in many tissues including heart, kidney, liver, uterus, bone marrow, lung, adipose tissue, and macrophages [20-22]. Its upregulation follows the activation of the NF-kB pathway [23]. NGAL was shown to play a pivotal role as a modulator of the innate immune system in inflammation [24-26]. Of note, the complex NGAL-MMP-9 extends the proteolytic activity of the latter by inhibiting its degradation [27], which leads to several pathophysiological conditions [28]. In human diseases, several studies have shown that NGAL increases significantly and rapidly in case of renal cell damage, suggesting that NGAL is a biomarker of various forms of kidney injuries [29,30]. NGAL upregulation could also be a biomarker in patients who suffer from heart failure [31] or in those who undergo cardiac surgery [32]. NGAL is upregulated in several other inflammatory states, like chronic obstructive pulmonary disorder and bowel inflammatory condition [33]. Strenuous exercise, causing oxidative stress and reactive oxygen species (ROSs) production, can induce changes in NGAL concentration as well [34-36]. Bongers et al. reported that prolonged endurance exercise in healthy adults could induce an increase in NGAL urinary concentration [34]. Increased NGAL urinary levels have also been found in endurance cycling athletes [35]. These findings were validated by Lippi et al., who demonstrated increased acute expression of serum NGAL in long distance running athletes (strenuous exercise) [36]. The expression of NGAL has also been investigated in physically active individuals, after short-term maximal exercise, but no differences in its expression have been reported [37,38]. However, the expression of NGAL in association with an AMTE protocol has never been investigated.

Another, recently emerging important compound positively associated with physical activity is represented by vitamin D. It is a fat-soluble molecule able to exert antioxidant functions, responsible for the body's mineral homeostasis. This vitamin can be taken exogenously with food or endogenously produced by the skin during the exposure to sunlight. After synthesis, vitamin D is inactive. The liver operates the conversion from the inactive form to 25-hydroxyvitamin $\mathrm{D}$ or calcidiol by hydroxylation at carbon 25. The latter is then collected in the adipose tissue as a reserve. To become active, 25-hydroxyvitamin D needs the participation of kidneys and 1-hydroxylase enzyme to be converted into 1,25-dihydroxyvitamin D, known as calcitriol [39]. The body cells respond to vitamin $\mathrm{D}$ in its active form through its receptor called vitamin D receptor (VDR) [40]. Vitamin D can regulate important mechanisms of immunity and inflammation and to modulate cardiovascular and musculoskeletal systems [41]. Indeed, it was shown that calcitriol suppresses NF-kB activity in a VDR-dependent manner. VDR binds IKK $\beta$, and this interaction is enhanced by calcitriol. Thus, VDR overexpression downregulates IKK $\beta$-induced NF- $\mathrm{KB}$ activity [42]. Its deficiency represents a risk factor for the onset of metabolic syndrome, but it also determines an increase in oxidative stress. Several studies indicate that physical activity promotes an increase in vitamin D level, despite sun exposure [43-46]. Indeed, it has been evidenced that the vitamin D receptor (VDR) increases during exercise $[47,48]$. These findings would suggest that physical activity exerts its positive effects also through the vitamin D pathway. Summing up, (i) physical activity is shown to increase the circulating levels of vitamin D [43-46]; (ii) vitamin $\mathrm{D}$ is also shown to exert its anti-inflammatory effects through the $\mathrm{NK}_{\mathrm{K} B} \mathrm{~B}$ inhibition [49]; and (iii) NGAL is shown to be upregulated by induction of the NF-kB pathway $[50,51]$. The question remains: Does AMTE have any effect on NGAL expression? If so, does the VDR expression change as well? The goal of the present research was to answer these questions and to evaluate the expression of NGAL and VDR in kidneys and hearts of rats subjected to AMTE for 12 weeks. 


\section{Materials and Methods}

\subsection{Breeding and Housing of Animals}

Sixteen 3-month-old healthy male Wistar Outbred Rats (Charles River Laboratories, Milan, Italy) with an average body weight of $300 \pm 20 \mathrm{~g}$ were housed in polycarbonate cages (cage dimensions: $\left.10.25^{\prime \prime} \mathrm{W} \times 18.75^{\prime \prime} \mathrm{D} \times 8^{\prime \prime} \mathrm{H}\right)$ at controlled temperature $\left(20-23^{\circ} \mathrm{C}\right)$ and humidity during the entire experimentation at the "Center for Advanced Preclinical In Vivo Research (CAPIR)". The animals had free access to food and water and lived a photoperiod of $12 \mathrm{~h}$ light/dark. The day after the last training (the experiment lasted 12 weeks), the rats were sacrificed by an intravenous lethal injection of anesthetic overdose using a mixture of Zoletil 100 (Virbac, Milan, Italy) at a dose of $80 \mathrm{mg} / \mathrm{kg}$ and DEXDOMITOR (Virbac, Milan, Italy) at a dose of $50 \mathrm{mg} / \mathrm{kg}$. After the sacrifice, kidney and heart were explanted and histological and immunohistochemical analyses were performed. All procedures conformed to the guidelines of the Institutional Animal Care and Use Committee (I.A.C.U.C.) of the University of Catania (Protocol n. 2112015-PR of the 14.01.2015, Italian Ministry of Health). The experiments were performed accordingly with the European Community Council Directive (86/609/EEC) and the Italian Animal Protection Law (116/1992).

\subsection{Experimental Design}

Sixteen 3-month-old healthy male Wistar Rats were randomly divided into two groups, with 8 rats per group:

- Group 1: sedentary rats.

- Group 2: rats undergoing AMTE on treadmill.

Group 2 rats performed moderate exercise on the treadmill (2Biological instrument, Varese, Italy), for 12 weeks, five days a week, for 20/30 min daily. The treadmill was set with an inclination of $2^{\circ}$ (between 2 and 6 degrees) and speed of 10/30 m/minute (type of exercise: interval training, between mild and moderate intensity). Physical activity was executed by the method previously described [52,53]. Briefly, a minimal electric shock $(0.2 \mathrm{~mA})$ forced the rat to walk on the treadmill. The shock serves to stimulate the rat to walk and to instruct it. Usually, the rat learns this activity in the first $2 \mathrm{~min}$ of the exercise. This type of exercise is used to stimulate the muscles, joints, and bones in the work of flexion-extension of the limbs. During the exercise, the possible suffering of the animals was evaluated. The rats that exceeded five electric shocks $(0.2 \mathrm{~mA})$ without learning the work to be done on the treadmill, have been discarded from the experiment. On the day following the last training (after 12 weeks of the experiment) the animals were humanely sacrificed by a lethal intravenous injection of anesthetic overdose, and kidney/heart samples were explanted and fixed for the histological and immunohistochemical analysis.

\subsection{Histology}

Kidney and heart samples were fixed in 10\% neutral buffered formalin (Bio-Optica, Milan, Italy). Embedding in paraffin followed overnight washing, as previously described [54]. The samples were placed in the cassettes after wax infiltration. A rotary manual microtome (Leica RM2235, Milan, Italy) was used to cut the paraffin blocks into tissue samples $(4-5 \mu \mathrm{m})$ which were then mounted on silane-coated slides (Menzel-Gläser, Braunschweig, Germany) and stored at room temperature. Histological analysis and examination of structural alterations were possible by dewaxing the sections in xylene, hydrating them by graded ethanol, and then staining with hematoxylin and eosin.

A Zeiss Axioplan light microscope (Carl Zeiss, Oberkochen, Germany) and a digital camera (AxioCam MRc5, Carl Zeiss, Oberkochen, Germany) were used to examine slides. 


\subsection{Immunohistochemistry}

Kidney and heart samples were processed for immunohistochemical evaluation as formerly discussed [55]. Thoroughly, the slides were dewaxed in xylene, hydrated by graded ethanol, incubated for $30 \mathrm{~min}$ in $0.3 \%$ hydroperoxyl $\left(\mathrm{H}_{2} \mathrm{O}_{2}\right)$ / methanol to block endogenous peroxidase activity, and then rinsed in phosphate-buffered saline (PBS; Bio-Optica, Milan, Italy) for $20 \mathrm{~min}$. The antigenic sites were unmasked by storing the slides in capped polypropylene slide holders with citrate buffer $(10 \mathrm{mM}$ citric acid, 0.05\% Tween 20, pH 6.0; Bio-Optica, Milan, Italy) and heated for 5 min for three times inside a microwave oven (750 W, LG Electronics Italia S.p.A., Milan, Italy). Nonspecific binding of the antibodies was prevented by the applying of a blocking buffer with $5 \%$ bovine serum albumin (BSA, Sigma, Milan, Italy) in PBS for one $h$ in a moist chamber, and then the primary antibodies were applied. The sections of tissue were then incubated overnight at $4{ }^{\circ} \mathrm{C}$ with the following antibodies; rat monoclonal anti-vitamin D receptor (ab115495; Abcam, Cambridge, UK) diluted 1/100 in PBS (Bio-Optica, Milan, Italy) and rabbit monoclonal anti-NGAL [EPR5084] (ab125075; Abcam, Cambridge, UK), diluted 1/100 in PBS (Bio-Optica, Milan, Italy). The slides were then covered with a biotinylated antibody (horseradish peroxidase (HRP)-conjugated anti-rat and anti-rabbit were used as secondary antibodies), and the peroxidase-labeled streptavidin allowed the detection of the immune complexes (labeled streptavidin-biotin (LSAB) + System-HRP, K0690, Dako, Glostrup, Denmark), after incubation for $10 \mathrm{~min}$ at room temperature. The immunoreaction was perceived by incubating the sections for $2 \mathrm{~min}$ in a $0.1 \% 3,3^{\prime}$-diaminobenzidine, $0.02 \%$ hydrogen peroxide solution (DAB substrate Chromogen System; Dako, Denmark). The slides were mildly counterstained with Mayer's Hematoxylin (Histolab Products AB, Goteborg, Sweden) and mounted in GVA mount (Zymed, Laboratories Inc., San Francisco, CA, USA).

\subsection{Computerised Densitometric Measurements and Image Analysis}

Image analysis software (AxioVision Release 4.8.2-SP2 Software, Carl Zeiss Microscopy GmbH, Jena, Germany) was used to quantify the grade of staining of positive anti-vitamin D receptor and anti-NGAL antibodies immunolabeling. It also calculated the densitometric count (Log2 densitometric count-pixel2) of the immunostained area in seven fields, the area of which was about 150,000 $\mathrm{m}^{2}$, randomly selected from slides. Digital micrographs were taken using the Zeiss Axioplan light microscope (Carl Zeiss, Oberkochen, Germany), using a lens with a magnification of $\times 20$, i.e., total magnification 200) fitted with a digital camera (AxioCam MRc5, Carl Zeiss, Oberkochen, Germany). Evaluations were performed by three blinded investigators (two anatomical morphologists and one histologist). The values were accepted as correct if they did not show statistically significant difference [56]. Every single interpretation of the results was discussed in favor of a standard agreement, in case of disputes [53].

\subsection{Statistical Analysis}

GraphPad Instat ${ }^{\circledR}$ Biostatistics version 3.0 software (GraphPad Software, Inc., La Jolla, CA, USA) and IBM SPSS Statistics (version 20, IBM Corporation, Somers, Armonk, NY, USA) were used as instruments of statistical evaluations. An unpaired $t$-test was used to compare two groups. $p$-values of less than 0.05 were considered statistically significant $\left({ }^{*} p<0.05 ;{ }^{* *} p<0.01 ; * * * p<0.001\right.$; ${ }^{* * * *} p<0.0001$ and ns not significant) as previously described [57]. The data were presented as the mean \pm SD.

\section{Results}

\subsection{Histology}

Hematoxylin \& eosin staining made possible to inspect morphological alterations in the kidney and heart tissue of the experimental groups. No damages in the histological structure of kidney and heart tissue were appreciated (data not shown). 


\subsection{Immunohistochemistry (IHC) Observations and Statistical Analysis}

\subsubsection{NGAL-Kidney}

NGAL immunostaining was mainly detected in the cytoplasm of cells in the medulla of kidney samples of both Groups, 1 and 2, involving collecting ducts and loops of Henle (Figure 1A,C). In the cortex, the NGAL immunostaining was found at the different degree in groups, involving both distal and proximal convoluted tubules; glomeruli were rarely and slightly immunostained (Figure 1B,D). The intensity of NGAL immunostaining (Log2 densitometric count-pixel2) was lower in Group 2 $(16.60 \pm 1.71)$ when compared to sedentary control group (Group 1) $(17.87 \pm 0.59)(p=0.0028)$, as reported in graph (Figure 1E).
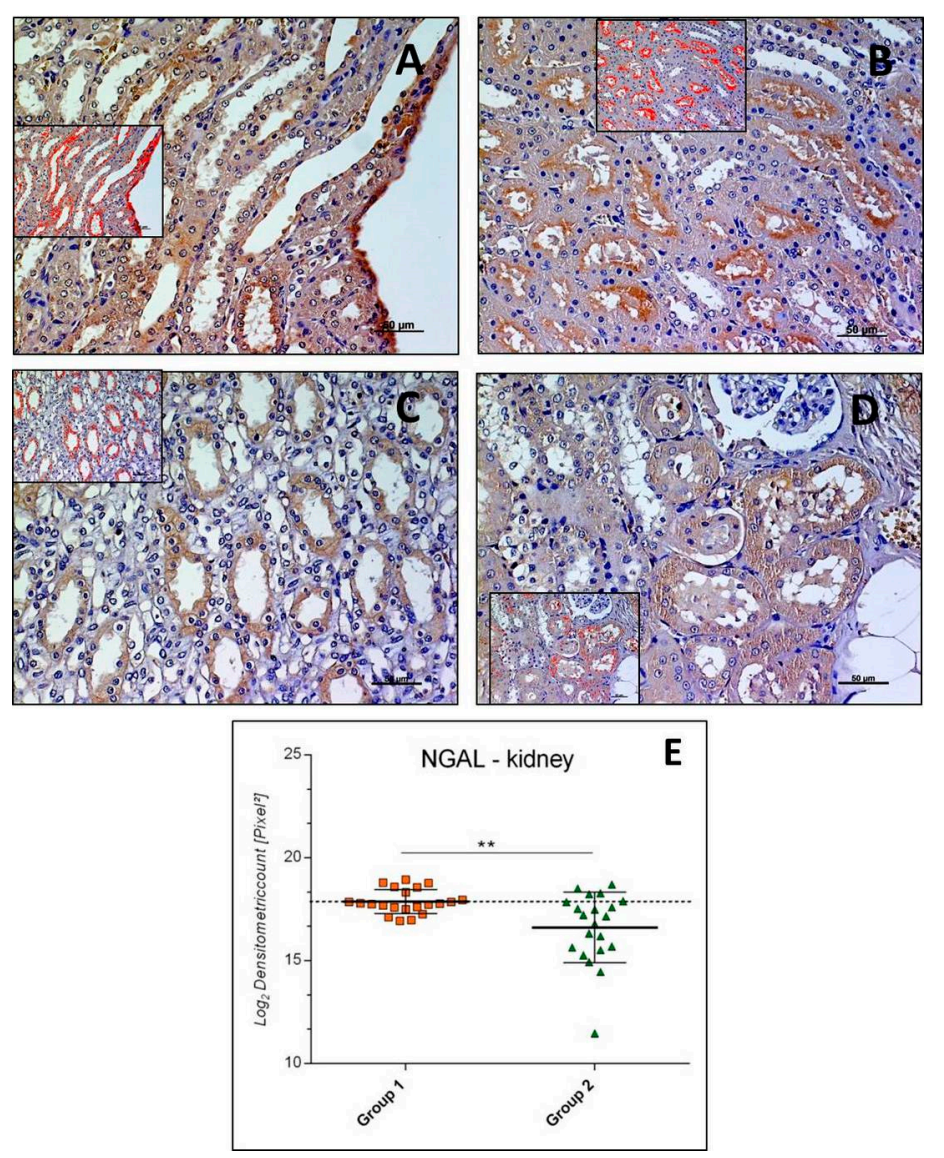

Figure 1. Kidney neutrophil gelatinase-associated lipocalin (NGAL) immunohistochemistry in Group $1(\mathbf{A}, \mathbf{B})$ and in Group 2 (C,D). NGAL immunostaining in kidney tissue and image analysis by software in which the red color indicates the immunolabeling (inserts). NGAL immunostaining was mainly detected in the medulla of kidney samples $(\mathbf{A}, \mathbf{C})$ and in the cortex where it was at a different degree in groups (B,D); glomeruli were rarely and slightly immunostained. (E) Graph showing the intensity of NGAL immunostaining $\left(\log _{2}\right.$ Densitometric count pixel $\left.{ }^{2}\right)$ with statistical analysis. For details, see the text. (A-D): scale bars: $50 \mu \mathrm{m}$. The data are presented as mean \pm SD.

\subsubsection{VDR-Kidney}

VDR immunostaining was highlighted both in cytoplasm and nucleus of cells in kidney samples of both Groups, 1 and 2. It had different expression levels in the collecting ducts and loops of Henle of the medulla (Figure 2A,C) and the distal and proximal convoluted tubules of the cortex (Figure 2B,D) about different groups. Glomeruli were rarely VDR immunostained. The intensity of VDR immunostaining (Log2 densitometric count-pixel2) was much higher in Group $2(18.15 \pm 0.71)$ when compared to Group $1(15.11 \pm 2.09)(p<0.0001)$, as reported in the graph (Figure 2E). 

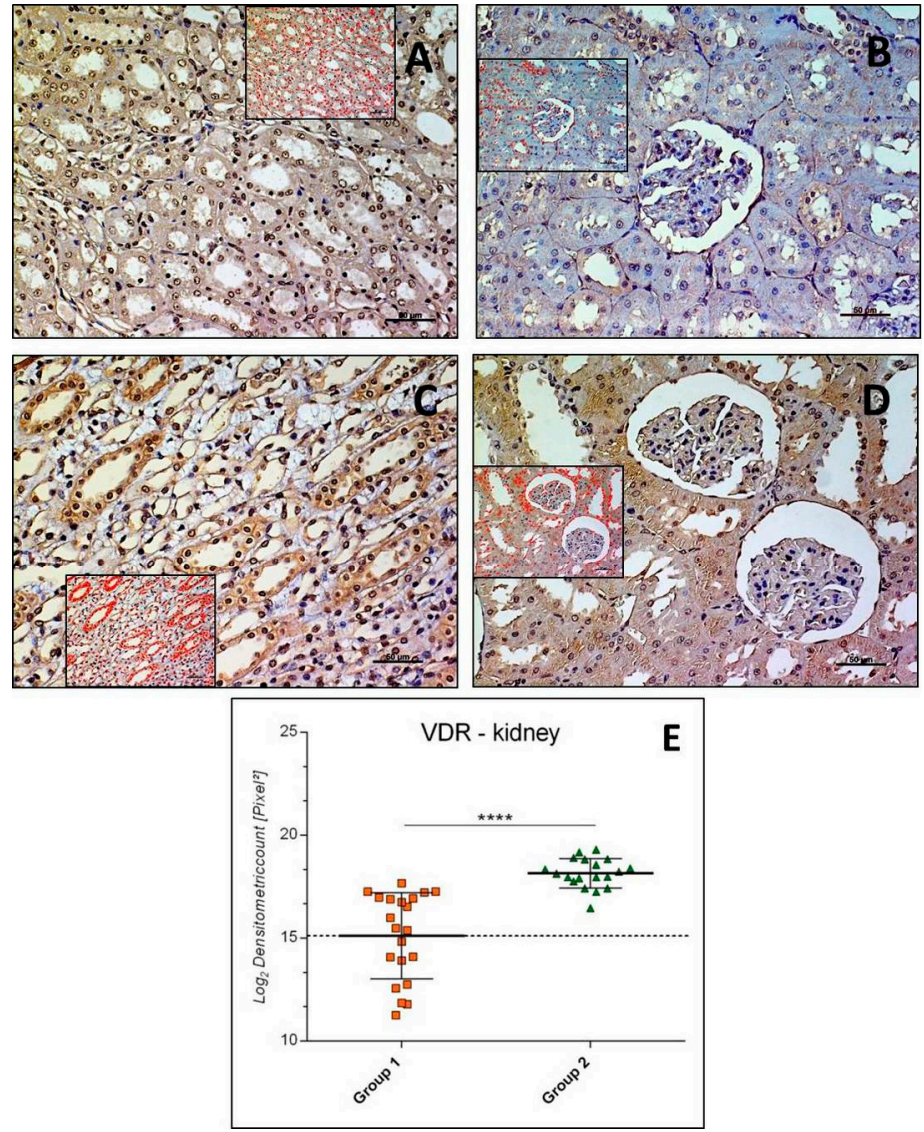

Figure 2. Kidney vitamin D receptor (VDR) immunohistochemistry in Group $1(\mathbf{A}, \mathbf{B})$ and in Group 2 (C,D). VDR immunostaining in kidney tissue and image analysis by software in which the red color indicates the immunolabeling (inserts). VDR immunostaining had different expression levels in the medulla $(\mathbf{A}, \mathbf{C})$ and in the cortex $(\mathbf{B}, \mathbf{D})$ in groups; glomeruli were rarely VDR immunostained. (E) Graph showing the intensity of VDR immunostaining ( $\log _{2}$ Densitometric count pixel ${ }^{2}$ ) with statistical analysis. For details, see the text. (A-D): scale bars: $50 \mu \mathrm{m}$. The data are presented as mean \pm SD.

\subsubsection{NGAL-Heart}

NGAL immunostaining was mainly detected in the cardiomyocytes cytoplasm of both Groups, 1 and 2 (Figure 3A,B). The intensity of NGAL immunostaining (Log2 densitometric count-pixel2) was almost equal in Group 2 (19.56 \pm 0.79$)$ if compared to Group 1 (sedentary) (19.48 \pm 0.89$)$, and the difference between means was not significant $(p=0.7655, \mathrm{~ns})$, as reported in the graph (Figure $3 \mathrm{C}$ ). 

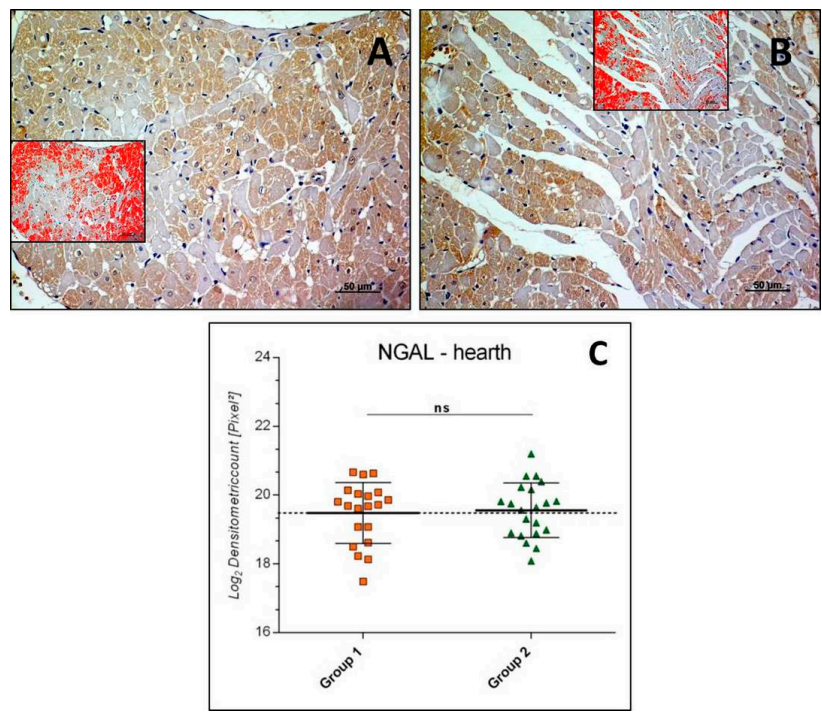

Figure 3. Heart NGAL immunohistochemistry in Group 1 (A) and Group 2 (B). NGAL immunostaining in heart tissue and image analysis by software in which the red color indicates the immunolabeling (inserts). NGAL immunostaining detected in the cytoplasm of cardiomyocytes, at similar levels of expression in the groups. (C) Graph showing the intensity of NGAL immunostaining ( $\log _{2}$ Densitometric count pixel $^{2}$ ) with statistical analysis. For details, see the text. (A,B): scale bars: $50 \mu \mathrm{m}$. The data are presented as mean \pm SD.

\subsubsection{VDR-Heart}

In heart samples, VDR immunostaining was detected mainly in the cytoplasm of cardiomyocytes of both Groups 1 and 2 (Figure 4A,B), and rarely in nuclei. The intensity of VDR immunostaining (Log2 densitometric count-pixel2) was similar both in Group 2 (19.11 \pm 0.79$)$ and Group 1 (sedentary) $(18.81 \pm 0.67)$ and the difference between means was not significant $(p=0.1847, \mathrm{~ns})$, as reported in the graph (Figure 4C).
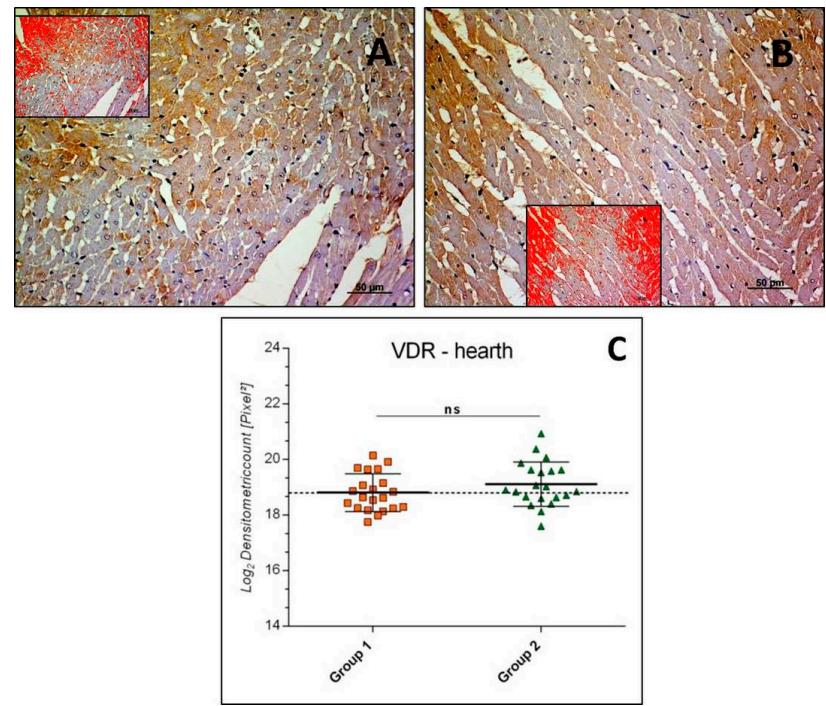

Figure 4. Heart VDR immunohistochemistry in Group 1 (A) and in Group 2 (B). VDR immunostaining in heart tissue and image analysis by software in which the red color indicates the immunolabeling (inserts). VDR immunostaining was found to have similar degrees of expression in the groups, mainly in the cardiomyocytes cytoplasm and rarely in nuclei. (C) Graph showing the intensity of VDR immunostaining ( $\log _{2}$ Densitometric count pixel $^{2}$ ) with statistical analysis. For details, see the text. $(\mathbf{A}, \mathbf{B})$ : scale bars: $50 \mu \mathrm{m}$. The data are presented as mean \pm SD. 


\section{Discussion}

The presented research aimed to assess if AMTE may exert a protective role on body homeostasis, through vitamin D and NGAL pathways. Our results, as expected, showed the augmented expression of VDR in kidneys of rats subjected to AMTE, in comparison to the sedentary controls. These results may hint an increased release of vitamin $\mathrm{D}$ in the circulation after physical activity, confirming findings from literature [43-46]. Makanae et al. demonstrated that indeed intramuscular VDR expression could be effectively promoted by physical activity [47]. Another work suggests that rats performing swimming activity experienced increases in vitamin D level in the serum and, consequently, a greater expression of its receptors in the pancreas, adipose tissue, and muscle [48]. In the present study, the authors did not evaluate the circulating levels of vitamin D in the serum of rats undergoing AMTE protocol; this represents a limitation of the study. Nevertheless, curiously, in our results, the expression of VDR in the heart of active rats did not change significantly when compared to the sedentary controls. A reason for that could be hypothesized by the fact that the circulating vitamin $\mathrm{D}$ is converted in its active form in the kidney and, then, determines the increased local expression of its receptor at this level, but does not determine its increase in other organs. Nevertheless, further long-term studies should be done to clarify this aspect. Vitamin D was shown to inhibit the NF-kB pathway $[24,25]$. Thus, since the promoter region of NGAL contains a consensus-binding site for NF- $\mathrm{KB}[58,59]$ and VDR was shown to inhibit the activation of NF- $\kappa B$, it is conceivable that increased levels of circulating vitamin $D$ indirectly inhibit the NGAL expression (Figure 5). In our work, we observed the basal expression of NGAL both in hearts and kidneys of sedentary rats, suggesting that sedentary lifestyle may represent a condition in which it is easier to develop NGAL-involved pathophysiological states. We also assisted to a significant reduction in the detection of NGAL in kidneys inactive rats, as expected, but curiously, not in their hearts. These data suggest that, regarding the crosslink between VDR and NGAL pathways, AMTE did not have any effects on heart tissue, but only on the kidney one. Moreover, a significant and inversely proportional expression of both proteins in kidneys, but not in hearts, of active rats, when compared to the sedentary controls, further confirms the involvement of VDR in the NGAL downregulation. This reasonably happened through the NF- $\mathrm{kB}$ inhibition. However, these preliminary findings certainly need further studies to confirm the crosslink between these two pathways. Albeit above reported scientific data highlight that physical activity may increase NGAL levels, they refer to strenuous anaerobic exercise. In our experimental design, we preferred to use AMTE, since this type of exercise is more inclined to induce an adaptive response by the body and our results were different from those reported concerning the strenuous anaerobic exercise. These findings have intriguing clinical implications related to physical activity in humans, emphasizing the beneficial effects of AMTE, but not strenuous exercise, particularly in obese people, given that obesity is associated with inflammation [60]. The limitations of our study refer to the nondosing of NGAL in organic liquids such as urine and blood, which could strengthen immunohistochemical data on tissue; this will lead us to further future studies to deepen the topic of our research. 


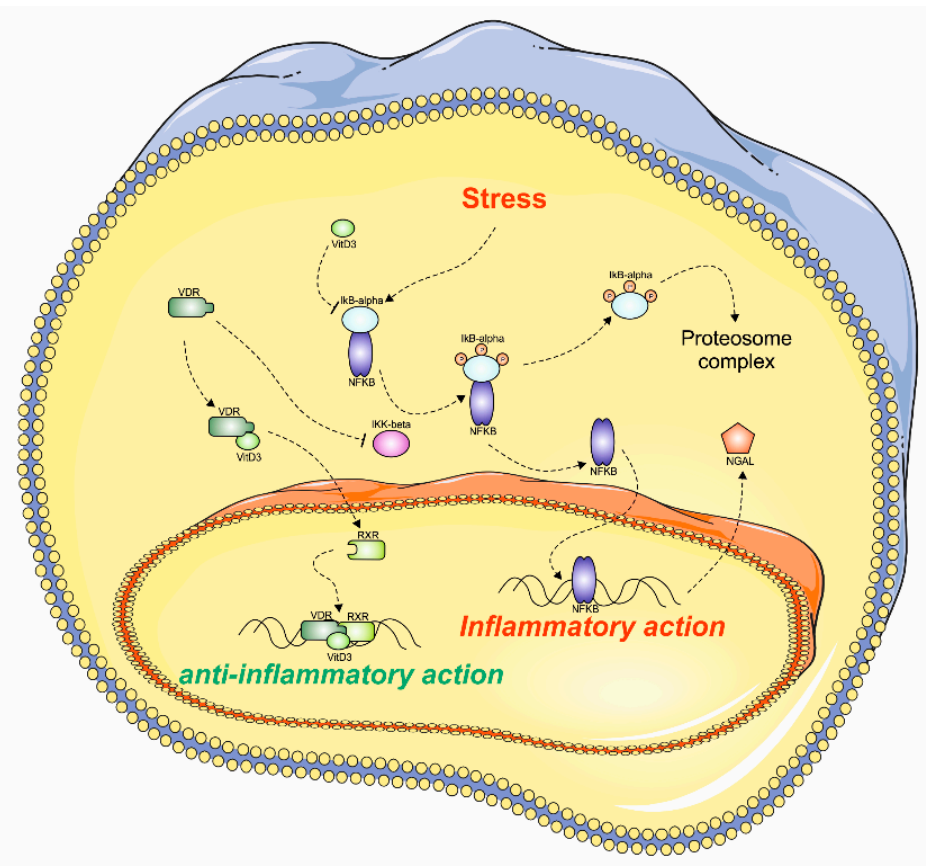

Figure 5. The possible VDR action on kidney cells. The hypothetical mechanism involved during the stress condition in kidney cells. The deprivation of vitamin D3 and stress condition determines the NKkB activation, which results in NGAL upregulation and inflammation. On the contrary, the increased levels of vitamin D3 may determine the inhibition of NFkB pathway, which indirectly may block NGAL synthesis, exerting its anti-inflammatory effect. This figure was drawn using the software CorelDraw (Version, Company, City, US State Abbr., Country and Year) and the vector image bank of Servier Medical Art (http:/ /smart.servier.com/). Servier Medical Art by Servier is licensed under a Creative Commons Attribution 3.0 Unported License (https:/ / creativecommons.org/licenses/by/3.0/).

\section{Conclusions}

In the present study, once again in agreement with the current literature, we provide experimental evidence supporting the concept that physical activity improves metabolic homeostasis, leading to physical wellness. We can also confirm the positive effects of physical activity-dependent vitamin D mobilization/synthesis, counteracted by NGAL behavior in the kidney. We believe that the present morphological study, although it has some limitations, can give an interesting contribution in basic research to better understand the role of molecule biomarkers for kidney injuries, such as NGAL, and, consequently, adopt strategies that can improve and maintain the state of health of the individual. However, additional investigations should be realized to confirm our preliminary morphological data.

Author Contributions: All authors contributed equally to the design of the study as well as results interpretation and concluding concepts. Conceptualization and Methodology, Writing-Original Draft, P.C.; Data Curation, Formal Analysis, Investigation, and Visualization: M.D.R.; Investigation: S.R. and F.M.T.; Resources: R.I. and L.M.; Methodology, Writing-Original Draft, and Investigation: M.A.S.; Conceptualization, Methodology, Writing-Review \& Editing, and Project Administration: G.M. All authors approved the final submitted version.

Funding: This research gained the support of the University Research Project Grant (Triennial Research Plan 2016-2018), Department of Biomedical and Biotechnological Sciences (BIOMETEC), University of Catania, Italy.

Acknowledgments: The authors would like to express their gratitude to Iain Halliday for his valuable work of correction of the paper.

Conflicts of Interest: The authors declare no conflicts of interest.

\section{References}

1. Roubenoff, R. Physical activity, inflammation, and muscle loss. Nutr. Rev. 2007, 65, S208-S212. [CrossRef] [PubMed] 
2. Castrogiovanni, P.; Imbesi, R. Oxidative stress and skeletal muscle in exercise. Ital. J. Anat. Embryol. 2012, 117, 107-117. [PubMed]

3. Ward-Ritacco, C.L.; Adrian, A.L.; Johnson, M.A.; Rogers, L.Q.; Evans, E.M. Adiposity, physical activity, and muscle quality are independently related to physical function performance in middle-aged postmenopausal women. Menopause 2014, 21, 1114-1121. [CrossRef] [PubMed]

4. Musumeci, G.; Loreto, C.; Imbesi, R.; Trovato, F.M.; Di Giunta, A.; Lombardo, C.; Castorina, S.; Castrogiovanni, P. Advantages of exercise in rehabilitation, treatment and prevention of altered morphological features in knee osteoarthritis. A narrative review. Histol. Histopathol. 2014, 29, 707-719. [CrossRef]

5. Moreira, L.D.; Oliveira, M.L.; Lirani-Galvão, A.P.; Marin-Mio, R.V.; Santos, R.N.; Lazaretti-Castro, M. Physical exercise and osteoporosis: Effects of different types of exercises on bone and physical function of postmenopausal women. Arq. Bras. Endocrinol. Metabol. 2014, 58, 514-522. [CrossRef]

6. Beiter, T.; Hoene, M.; Prenzler, F.; Mooren, F.C.; Steinacker, J.M.; Weigert, C.; Nieß, A.M.; Munz, B. Exercise, skeletal muscle and inflammation: ARE-binding proteins as key regulators in inflammatory and adaptive networks. Exerc. Immunol. Rev. 2015, 21, 42-57.

7. Castrogiovanni, P.; Trovato, F.M.; Szychlinska, M.A.; Nsir, H.; Imbesi, R.; Musumeci, G. The importance of physical activity in osteoporosis. From the molecular pathways to the clinical evidence. Histol. Histopathol. 2016, 31, 1183-1194. [CrossRef]

8. Du, Z.; Li, Y.; Li, J.; Zhou, C.; Li, F.; Yang, X. Physical activity can improve cognition in patients with Alzheimer's disease: A systematic review and meta-analysis of randomized controlled trials. Clin. Interv. Aging 2018, 13, 1593-1603. [CrossRef]

9. Musumeci, G.; Castrogiovanni, P.; Coleman, R.; Szychlinska, M.A.; Salvatorelli, L.; Parenti, R.; Magro, G.; Imbesi, R. Somitogenesis: From somite to skeletal muscle. Acta Histochem. 2015, 117, 313-328. [CrossRef]

10. Musumeci, G.; Trovato, F.M.; Imbesi, R.; Castrogiovanni, P. Effects of dietary extra-virgin olive oil on oxidative stress resulting from exhaustive exercise in rat skeletal muscle: A morphological study. Acta Histochem. 2014, 116, 61-69. [CrossRef]

11. Coqueiro, R.D.S.; Soares, T.J.; Pereira, R.; Correia, T.M.L.; Coqueiro, D.S.O.; Oliveira, M.V.; Marques, L.M.; de Sá, C.K.C.; de Magalhães, A.C.M. Therapeutic and preventive effects of exercise on cardiometabolic parameters in aging and obese rats. Clin. Nutr. ESPEN 2019, 29, 203-212. [CrossRef]

12. Martínez, R.; Kapravelou, G.; López-Chaves, C.; Cáceres, E.; Coll-Risco, I.; Sánchez-González, C.; Llopis, J.; Arrebola, F.; Galisteo, M.; Aranda, P.; et al. Aerobic interval exercise improves renal functionality and affects mineral metabolism in obese Zucker rats. Am. J. Physiol. Renal. Physiol. 2019, 316, F90-F100. [CrossRef]

13. Ranjbar, K.; Nazem, F.; Sabrinezhad, R.; Nazari, A. Aerobic training and L-arginine supplement attenuates myocardial infarction-induced kidney and liver injury in rats via reduced oxidative stress. Indian Heart $J$. 2018, 70, 538-543. [CrossRef]

14. Choi, K.M.; Kim, T.N.; Yoo, H.J.; Lee, K.W.; Cho, G.J.; Hwang, T.G.; Baik, S.H.; Choi, D.S.; Kim, S.M. Effect of exercise training on A-FABP, lipocalin-2 and RBP4 levels in obese women. Clin. Endocrinol. 2009, 70, 569-574. [CrossRef]

15. Musumeci, G.; Aiello, F.C.; Szychlinska, M.A.; Di Rosa, M.; Castrogiovanni, P.; Mobasheri, A. Osteoarthritis in the XXIst century: Risk factors and behaviours that influence disease onset and progression. Int. J. Mol. Sci. 2015, 16, 6093-6112. [CrossRef]

16. Musumeci, G. Sarcopenia and Exercise "The State of the Art". J. Funct. Morphol. Kinesiol. 2017, 2, 40. [CrossRef]

17. Musumeci, G. The Use of Vibration as Physical Exercise and Therapy. J. Funct. Morphol. Kinesiol. 2017, 2, 17. [CrossRef]

18. Castrogiovanni, P.; Di Giunta, A.; Guglielmino, C.; Roggio, F.; Romeo, D.; Fidone, F.; Imbesi, R.; Loreto, C.; Castorina, S.; Musumeci, G. The Effects of Exercise and Kinesio Tape on Physical Limitations in Patients with Knee Osteoarthritis. J. Funct. Morphol. Kinesiol. 2016, 1, 355-368. [CrossRef]

19. Kjeldsen, L.; Bainton, D.F.; Sengelov, H.; Borregaard, N. Identification of neutrophil gelatinase-associated lipocalin as a novel matrix protein of specific granules in human neutrophils. Blood 1994, 83, 799-807.

20. Xu, S.Y.; Carlson, M.; Engstrom, A.; Garcia, R.; Peterson, C.G.; Venge, P. Purification and characterization of a human neutrophil lipocalin (HNL) from the secondary granules of human neutrophils. Scand. J. Clin. Lab. Investig. 1994, 54, 365-376. [CrossRef] 
21. Sivalingam, Z.; Larsen, S.B.; Grove, E.L.; Hvas, A.M.; Kristensen, S.D.; Magnusson, N.E. Neutrophil gelatinase-associated lipocalin as a risk marker in cardiovascular disease. Clin. Chem. Lab. Med. 2017, 56, 5-18. [CrossRef] [PubMed]

22. Flo, T.H.; Smith, K.D.; Sato, S.; Rodriguez, D.J.; Holmes, M.A.; Strong, R.K.; Akira, S.; Aderem, A. Lipocalin 2 mediates an innate immune response to bacterial infection by sequestrating iron. Nature 2004, 432, 917-921. [CrossRef]

23. Li, S.H.; Hawthorne, V.S.; Neal, C.L.; Sanghera, S.; Xu, J.; Yang, J.; Guo, H.; Steeg, P.S.; Yu, D. Upregulation of neutrophil gelatinase-associated lipocalin by ErbB2 through nuclear factor-kappaB activation. Cancer Res. 2009, 69, 9163-9168. [CrossRef]

24. Goetz, D.H.; Holmes, M.A.; Borregaard, N.; Bluhm, M.E.; Raymond, K.N.; Strong, R.K. The neutrophil lipocalin NGAL is a bacteriostatic agent that interferes with siderophore-mediated iron acquisition. Mol. Cell. 2002, 10, 1033-1043. [CrossRef]

25. Nasioudis, D.; Witkin, S.S. Neutrophil gelatinase-associated lipocalin and innate immune responses to bacterial infections. Med. Microbiol. Immunol. 2015, 204, 471-479. [CrossRef] [PubMed]

26. Lisowska-Myjak, B.; Skarżyńska, E.; Wilczyńska, P.; Jakimiuk, A. Correlation between the concentrations of lactoferrin and neutrophil gelatinase-associated lipocalin in meconium. Biometals 2018, 31, 123-129. [CrossRef] [PubMed]

27. Yan, L.; Borregaard, N.; Kjeldsen, L.; Moses, M.A. The high molecular weight urinary matrix metalloproteinase (MMP) activity is a complex of gelatinase B/MMP-9 and neutrophil gelatinase-associated lipocalin (NGAL). Modulation of MMP-9 activity by NGAL. J. Biol. Chem. 2001, 276, 37258-37265. [CrossRef]

28. Hemdahl, A.L.; Gabrielsen, A.; Zhu, C.; Eriksson, P.; Hedin, U.; Kastrup, J.; Thorén, P.; Hansson, G.K. Expression of neutrophil gelatinase-associated lipocalin in atherosclerosis and myocardial infarction. Arterioscler. Thromb. Vasc. Biol. 2006, 26, 136-142. [CrossRef]

29. Mishra, J.; Mori, K.; Ma, Q.; Kelly, C.; Yang, J.; Mitsnefes, M.; Barasch, J.; Devarajan, P. Amelioration of ischemic acute renal injury by neutrophil gelatinase-associated lipocalin. J. Am. Soc. Nephrol. 2004, 15, 3073-3082. [CrossRef]

30. Mishra, J.; Dent, C.; Tarabishi, R.; Mitsnefes, M.M.; Ma, Q.; Kelly, C.; Ruff, S.M.; Zahedi, K.; Shao, M.; Bean, J.; et al. Neutrophil gelatinase-associated lipocalin (NGAL) as a biomarker for acute renal injury after cardiac surgery. Lancet 2005, 365, 1231-1238. [CrossRef]

31. Yndestad, A.; Landro, L.; Ueland, T.; Dahl, C.P.; Flo, T.H.; Vinge, L.E.; Espevik, T.; Frøland, S.S.; Husberg, C.; Christensen, G.; et al. Increased systemic and myocardial expression of neutrophil gelatinase-associated lipocalin in clinical and experimental heart failure. Eur. Heart. J. 2009, 30, 1229-1236. [CrossRef] [PubMed]

32. Haase-Fielitz, A.; Bellomo, R.; Devarajan, P.; Bennett, M.; Story, D.; Matalanis, G.; Frei, U.; Dragun, D.; Haase, M. The predictive performance of plasma neutrophil gelatinase-associated lipocalin (NGAL) increases with grade of acute kidney injury. Nephrol. Dial. Transplant. 2009, 24, 3349-3354. [CrossRef] [PubMed]

33. Nymo, S.H.; Hartford, M.; Ueland, T.; Yndestad, A.; Lorentzen, E.; Truvé, K.; Karlsson, T.; Ravn-Fischer, A.; Aukrust, P.; Caidahl, K. Serum neutrophil gelatinase-associated lipocalin (NGAL) concentration is independently associated with mortality in patients with acute coronary syndrome. Int. J. Cardiol. 2018, 262, 79-84. [CrossRef] [PubMed]

34. Bongers, C.C.W.G.; Alsady, M.; Nijenhuis, T.; Hartman, Y.A.W.; Eijsvogels, T.M.H.; Deen, P.M.T.; Hopman, M.T.E. Impact of acute versus repetitive moderate intensity endurance exercise on kidney injury markers. Physiol. Rep. 2017, 5. [CrossRef] [PubMed]

35. Machado, J.C.Q.; Volpe, C.M.O.; Vasconcellos, L.S.; Nogueira-Machado, J.A. Quantification of NGAL in Urine of Endurance Cycling Athletes. J. Phys. Act. Health 2018, 15, 679-682. [CrossRef] [PubMed]

36. Lippi, G.; Sanchis-Gomar, F.; Salvagno, G.L.; Aloe, R.; Schena, F.; Guidi, G.C. Variation of serum and urinary neutrophil gelatinase associated lipocalin (NGAL) after strenuous physical exercise. Clin. Chem. Lab. Med. 2012, 50, 1585-1589. [CrossRef] [PubMed]

37. Kanda, K.; Sugama, K.; Sakuma, J.; Kawakami, Y.; Suzuki, K. Evaluation of serum leaking enzymes and investigation into new biomarkers for exercise-induced muscle damage. Exerc. Immunol. Rev. 2014, 20, 39-54.

38. Wołyniec, W.; Ratkowski, W.; Urbański, R.; Bartoszewicz, M.; Siluk, D.; Wołyniec, Z.; Kasprowicz, K.; Zorena, K.; Renke, M. Urinary Kidney Injury Molecule-1 but Not Urinary Neutrophil Gelatinase Associated Lipocalin Is Increased after Short Maximal Exercise. Nephron 2018, 138, 29-34. [CrossRef] 
39. Nair, R.; Maseeh, A. Vitamin D: The "sunshine" vitamin. J. Pharmacol. Pharmacother. 2012, 3, 118-126.

40. Pike, J.W.; Meyer, M.B. The vitamin D receptor: New paradigms for the regulation of gene expression by 1,25-dihydroxyvitamin D3. Rheum. Dis. Clin. N. Am. 2012, 38, 13-27. [CrossRef]

41. Lombardi, G.; Corsetti, R.; Lanteri, P.; Grasso, D.; Vianello, E.; Marazzi, M.G.; Graziani, R.; Colombini, A.; Galliera, E.; Corsi-Romanelli, M.M.; et al. Reciprocal regulation of calcium-/phosphate-regulating hormones in cyclists during the Giro d'Italia 3-week stage race. Scand. J. Med. Sci. Sports 2014, 24, 779-787. [CrossRef]

42. Cohen-Lahav, M.; Shany, S.; Tobvin, D.; Chaimovitz, C.; Douvdevani, A. Vitamin D decreases NFkappaB activity by increasing IkappaBalpha levels. Nephrol. Dial. Transplant. 2006, 21, 889-897. [CrossRef]

43. Scott, D.; Ebeling, P.R.; Sanders, K.M.; Aitken, D.; Winzenberg, T.; Jones, G. Vitamin D and physical activity status: Associations with five-year changes in body composition and muscle function in community-dwelling older adults. J. Clin. Endocrinol. Metab. 2015, 100, 670-678. [CrossRef]

44. Gerdhem, P.; Ringsberg, K.A.M.; Obrant, K.J.; Akesson, K. Association between 25-hydroxy vitamin D levels, physical activity, muscle strength and fractures in the prospective population-based OPRA study of elderly women. Osteoporos. Int. 2005, 16, 1425-1431. [CrossRef]

45. Scott, D.; Blizzard, L.; Fell, J.; Ding, C.; Winzenberg, T.; Jones, G. A prospective study of the associations between 25 -hydroxyvitamin D, sarcopenia progression, and physical activity in older adults. Clin. Endocrinol. (Oxf.) 2010, 73, 581-587. [CrossRef]

46. Bell, N.H.; Godsen, R.N.; Henry, D.P.; Shary, J.; Epstein, S. The effects of muscle-building exercise on vitamin D and mineral metabolism. J. Bone Miner. Res. 1988, 3, 369-373. [CrossRef]

47. Makanae, Y.; Ogasawara, R.; Sato, K.; Takamura, Y.; Matsutani, K.; Kido, K.; Shiozawa, N.; Nakazato, K.; Fujita, S. Acute bout of resistance exercise increases vitamin D receptor protein expression in rat skeletal muscle. Exp. Physiol. 2015, 100, 1168-1176. [CrossRef]

48. Aly, Y.E.; Abdou, A.S.; Rashad, M.M.; Nassef, M.M. Effect of exercise on serum vitamin D and tissue vitamin D receptors in experimentally induced type 2 Diabetes Mellitus. J. Adv. Res. 2016, 7, 671-679. [CrossRef]

49. Chen, Y.; Zhang, J.; Ge, X.; Du, J.; Deb, D.K.; Li, Y.C. Vitamin D receptor inhibits nuclear factor $\kappa B$ activation by interacting with IкB kinase $\beta$ protein. J. Biol. Chem. 2013, 288, 19450-19458. [CrossRef]

50. Bu, D.X.; Hemdahl, A.L.; Gabrielsen, A.; Fuxe, J.; Zhu, C.; Eriksson, P.; Yan, Z.Q. Induction of neutrophil gelatinase-associated lipocalin in vascular injury via activation of nuclear factor-kappaB. Am. J. Pathol. 2006, 169, 2245-2253. [CrossRef]

51. Husi, H.; Human, C. Molecular determinants of acute kidney injury. J. Inj. Violence Res. 2015, 7, 75-86. [CrossRef] [PubMed]

52. Musumeci, G.; Trovato, F.M.; Pichler, K.; Weinberg, A.M.; Loreto, C.; Castrogiovanni, P. Extra-virgin olive oil diet and mild physical activity prevent cartilage degeneration in an osteoarthritis model: An in vivo and in vitro study on lubricin expression. J. Nutr. Biochem. 2013, 24, 2064-2075. [CrossRef] [PubMed]

53. Musumeci, G.; Castrogiovanni, P.; Trovato, F.M.; Imbesi, R.; Giunta, S.; Szychlinska, M.A.; Loreto, C.; Castorina, S.; Mobasheri, A. Physical activity ameliorates cartilage degeneration in a rat model of aging: A study on lubricin expression. Scand. J. Med. Sci. Sports 2015, 25, e222-e230. [CrossRef] [PubMed]

54. Trovato, F.M.; Imbesi, R.; Conway, N.; Castrogiovanni, P. Morphological and functional aspects of human skeletal muscle. J. Funct. Morphol. Kinesiol. 2016, 1, 289-302. [CrossRef]

55. Leonardi, R.; Rusu, M.C.; Loreto, F.; Loreto, C.; Musumeci, G. Immunolocalization and expression of lubricin in the bilaminar zone of the human temporomandibular joint disc. Acta Histochem. 2012, 114, 1-5. [CrossRef] [PubMed]

56. Musumeci, G.; Magro, G.; Cardile, V.; Coco, M.; Marzagalli, R.; Castrogiovanni, P.; Imbesi, R.; Graziano, A.C.; Barone, F.; Di Rosa, M.; et al. Characterization of matrix metalloproteinase-2 and -9, ADAM-10 and N-cadherin expression in human glioblastoma multiforme. Cell Tissue Res. 2015, 362, 45-60. [CrossRef] [PubMed]

57. Musumeci, G.; Mobasheri, A.; Trovato, F.M.; Szychlinska, M.A.; Graziano, A.C.; Lo Furno, D.; Avola, R.; Mangano, S.; Giuffrida, R.; Cardile, V. Biosynthesis of collagen I, II, RUNX2 and lubricin at different time points of chondrogenic differentiation in a $3 \mathrm{D}$ in vitro model of human mesenchymal stem cells derived from adipose tissue. Acta Histochem. 2014, 116, 1407-1417. [CrossRef]

58. Cowland, J.B.; Sørensen, O.E.; Sehested, M.; Borregaard, N. Neutrophil gelatinase-associated lipocalin is up-regulated in human epithelial cells by IL-1 beta, but not by TNF-alpha. J. Immunol. 2003, 171, 6630-6639. [CrossRef] 
59. Fuchs, O. Transcription factor NF- $\mathrm{BB}$ inhibitors as single therapeutic agents or in combination with classical chemotherapeutic agents for the treatment of hematologic malignancies. Curr. Mol. Pharmacol. 2010, 3, 98-122. [CrossRef]

60. Deng, T.; Lyon, C.J.; Bergin, S.; Caligiuri, M.A.; Hsueh, W.A. Obesity, Inflammation, and Cancer. Annu. Rev. Pathol. 2016, 11, 421-449. [CrossRef] 